in the debate pointed out that it is precisely the smaller periodicals and other institutions with limited resources which are at present most handicapped and obliged to exercise a severe prudence, and matters which it may be in the public interest to disclose or discuss are not revealed. On the whole, the issues were fairly stated in the debate, and sufficient goodwill was manifested on all sides to warrant the hope that a reasonable balance will be struck between the public interest in the way of information, and responsible comment and tho individual right of protection against damage.

\section{JOSIAH WILLARD GIBBS}

\section{Josiah Willard Gibbs}

The History of a Great Mind. By Lynde Phelps Wheeler. Pp. xi+264+9 plates. (New Haven, Conn.: Yale University Press; London: Oxford University Press, 1951.) 25s. net.

T HIS biography, by a pupil of Gibbs, is the first complete and critical account of his life and of the development of his work. A brief memoir by Bumstead was printed in the collected works, and other accounts have been written, which unfortunately were intended to illustrate rather distorted views of his genius. In the present work Prof. L. P. Wheeler has made full use of new material collected by the Gibbs family, particularly a collection of "Personal Recollections and Impressions of J. Willard Gibbs", which is now in the Yale University Library, and also of his surviving papers and letters. The book throws a good deal of new light on the origins of Gibbs's work and does much to put it in a proper perspective. It is interesting, though not surprising considering the American background at this time, to find that Gibbs's first studies were in practical engineering, and his Ph.D. at Yale University was the first to be awarded in the United States for engineering and the second for science as a whole. In these early years he applied himself to a projected "center-vent turbine" which did not materialize and to an improved brake for railway cars, which did receive a patent later in 1866 . He also published a careful discussion of the units used in mechanics.

It was with this apparently practical bent and outlook that Gibbs went to Europe in 1866. He first visited Paris, where he injured his health by attending sixteen lectures a week-and no doubt reading all the classic memoirs of French mathematical physics. In Berlin (1867) and Heidelberg (1868-69) he learnt to moderate his studies, and also became fully acquainted with German physics teaching and methods of work, which were to provide the model for his own work. There is nothing to indicate that he had close relations with the professors whose lectures he attended; and the lecture notes which have survived are not very detailed.

There is little in this to prepare us for the classic papers on thermodynamics which appeared between 1873 and 1878. Most great scientific workers have left at least some apprentice efforts to show how their ideas germinated and how they developed. With Gibbs, on his return to Yale there is, first, an improvement of the Watt pendulum governor, then in 1873 the paper on the use of graphical methods in the thermodynamics of fluids--a paper which, though comparatively simple, was the basis of the subsequent development-and then, within a few years, the great papers on heterogeneous equilibrium which show a complete understanding of all the possibilities and how to formulate them and a complete mastery of the method and full confidence.

It would be a revealing study of human nature if one could know what went on in the mind of this quiet, unassuming and friendly man; by what process the fragmentary and ill-understood knowledge of the time was integrated into this great and enduring synthesis. Gibbs has often been praised for the thoroughness of his memoir - the fact that he explored, once and for all, nearly all the consequences of the second law of thermodynamics, so far as they can be applied to chemical equilibrium. But he himself thought otherwise in his later years. In a letter to Lord Rayleigh he said, "I thank you very much for your kind interest in my 'Equil. Het. Subs.'. I myself had come to the conclusion that the fault was that it was too long. I do not think I had any sense of the value of time, of my own or of others, when I wrote it". It is perhaps true that some of the relations discovered are trivial, and many concerned possibilities which have remained uninvestigated until the present day. The details certainly obscured the ready understanding of the great fundamental equations of chemical thermodynamics.

Although the memoirs were published in the rather obscure Transactions of the Connecticut Academy-a periodical with a small circulation-it is not true, as is sometimes stated, that Gibbs was indifferent to their recognition. $\mathrm{He}$ himself distributed about ninety copies of the memoirs to a list of names which included most of the best-known European physicists.

Prof. Wheeler gives a very lucid account of Gibbs's later work on optics and on statistical mechanics. In both these fields Gibbs showed the same mastery of essentials and power of synthesis as was shown in the thermodynamies. The work on optics was rather overshadowed by parallel developments in Europe ${ }^{1}$. The masterly nature of the work on statistical mechanics is now well recognized. Gibbs was perhaps a little unfortunate in coming just before the develop. ment of the quantum theory provided a body of experimental material to which his method could be applied, but his approach was so sound that it could accommodate the quantum theory without any difficulty. He sought a comprehensive theory embracing all physical phenomena, yet, while he was aware of the impossibility of completing such a theory, the foundations he laid have proved to be perfectly adequate. "In the present state of science," he wrote, "it seems hardly possible to form a dynamical theory of molecular action which shall embrace the phenomena of thermodynamics, of radiation and of the electrical manifestations which accompany the union of atoms. Yet any theory is obviously inadequate which does not take account of all these phenomena."

All students of the physical sciences should read this book for the deep insight it gives into the development of a mathematical description of the physical world. Edward Jenner said, "Why think ?Try the experiment". Gibbs's life may well be held to illustrate the contrary adage. No doubt both have their place, but Gibbs, more than any other man of science of his time, had a clear appreciation of where thinking was appropriate and where experiment was necessary. J. A. V. ButLer

'For a study of Gibbs's method in optics, see Wheeler, I. T., Proc. U.S. Nat. Acad. Sei., 37, 850 (1951). 